die Wirksamkeit des Recvalysatıms Biirger experimentell schwer bo. weisen, wie schon Kionka von der Droge im allgenıeinen sagt: ,Ueber die Wirkung anf das Nervensystem kann ich ans meinen Versuchen nichts sagen." $)^{2}$

Wenn wir diese Gesichtspunkte richtig einschätzen, so verstehen wir, daß die synthetische Chemie bis zur Stunde noch kein Präparat erzeugen konnte, das die Vollwirksankeit der frischen Wnrzel ersetzt oder ihr gleichkommt. Wir mïssen vielmehr ancrkennen, daß die Natur lıier wieder eine künstlich nicht zu erzielende, nnübertreffliche Mischnng an wirksamen Bestandteilen schuf. Erfrenlicherweise wurde nenerdings wieder der Weg besclıritten, ein galenisches Prüparat zı el'zengen, dessen Anfgabe es ist: die Vollwirksamkeit der frischen Wurzel danernd und unverändert zn vermitteln. Ich habe das Bürgersche ,Recvalysatını" (RECens VALeriana DialYSATUM) im Vertranen anf seine Hertsellıngsweise nach dem Bïrgerschen Dialysierverfalıren angewandt. An beiden Präparaten ist besonders wertvoll, daß sie nns die gesamte Droge zur Verfügnng stellen, indem das unendlich leicht zerstörbare natiirliclıe Moleknlargebäude der frischen Pflanze erlialten bleibt; die bekannteıl Mängel der offizinellen Zubereitıngen sind glücklich vermieden.

Nach diesen Erwägnngen durfte ich das Präparat klinisch ansprobieren, ancl ${ }_{1}$ olıne daß experimentelle Tierversıche voransgegange wären. Beim jetzigen Stand der Erkenntnis wird nns nur dic therapentische Anwendung Sclılüsse anf die Wirksanıkeit des Mittels zullassen.

Im Herstellungsverfahren ans frisclier, ungetrockneter Wurzel lingt der bessere Gerıch und Geschmack begründet, wodırch sich Recvalysatım Bürger von der Tinct. Rad. Valerianae off. auszeiclınet. Daher stößt die Medikation selbst bei solchen Patienten, welche vielleicht schon mit Baldrian überfiittert sind, anf keinen Widerstand, namentlich, wenn man offen erklärt, daß hier ein wesentlich verbessertes Mittel vorliegt. Irgendwelche unerw ünschten oder gar toxischen Nebenersclieinungen traten bei der Anwendıng nicht anf; jedoch lege iclı b ssonderen Naclıdruck auf die leichte, digitalisälınliche Herzwirknıng des Recvalysats und auf seine gute Verträglichkeit seitens der Verdauungsorgane. Seinem Preis nach $(30 \mathrm{ccm}$ zil 1,25 M bzw. $60 \mathrm{ccm}$ zu $2 \mathrm{M}$ ) stellt es einen Fortschritt dar, wenn man seine sichere Vollwirksamkeit anch nocl mit berücksichtigt.

In der Privatpraxis verordne ich das Präparat seit etwa seclss Monaten, in Krankenhaus seit etwa einem Vierteljahr, zll welcheml Zwecke mir die Fabrik, Apotheker Johannes Bürger (Wernigerode), ansreichendes Versnclismaterial zur Verfiignng stellte.

Recvalysat wurde in allen Fällen, wo Baldrian, Brom oder leiclıte Schlafmittel angezeigt waren, gegeben. Iclı war mir darüber klar, daß ich in dieser vielseitigen Versuchsreihe das Mittel stets nur rein geben durfte, nm mir ein klares, durch keine Zusätze beeinflußtes Urteil zı bilden. Naclıdenı dies jetzt für mich feststelıt, bin ich in geeigneten Fällen anch dazı iibergegangen, Recvalysat mit anderen Mitteln z.11 verbinden.

Die genanesten Beobaolıtıngen versehafften mir die Fälle aus

Aus dem Krankenhaus des Zentraldiakonissenhauses ${ }_{n}$ Bethanien“ in Berlin.

\section{Recvalysat, ein wirksames Präparat der frischen Baldrianwurzel.}

Von Dr. Konrad Liepelt, stellvertretender Chefarzt der Inneren Abteilung.

Der Baldrian ist seit nndenklichen Zeiten als Hoilmittel gebraucht, viel gerülımt und ebenso lı̈̈ıfig als ınwirksan verworfe 1 . Merkwïrdig ist bei dieser Tatsachenlage, daß die Chenie sich so spät erst mit der Baldrianwurzel beschäftigt lrat. Gruıdlegende Untersuclungen stanmen von Poucliet und Chevalier ${ }^{2}$, Kionk $a^{3}$ ) nnd den Assistenten des Jenaer Institutes.

Als einzig sicller scleint festgestellt zu sein, daß die natiirliche cliemische Zusannnensetzung der frischen Wurzel bein 'Trockenprozeß durcl Einwirkung ciner Oxydase verändert wird. Dies ist der Grund fiil' die lıäıfig beklagte therapeutische Minderwertigkeit der getrockneten Wurzel, da die hierbei entstehende Baldriansäure so gut wie ınwirksam ist, jedenfalls andere Wirkungen äußert, als das ans der frischen Rad. valerianae erlialtene Dialysat Bürger. Und wenn cs riclitig ist, daß beim Trocknen der Baldrianwurzel starke Verändernngen in ilırer chemischen Zusammensetzung entstelsen und die Wirkung des Dialysates aus frischen Wurzeln erst den Anforderungen entspricht, die voun Baldrian erwartet werden köınen, so miissen unerforschte chemische Bestandteile vorhandeı sein, die der friselıen, nicht aber der getrocknete 11 Wırzel zukommen.

Da die Hauptwirkung als rein funktionell bei dem Syuptomenkomplex der „Nervosität" betrachtet werden darf, so läßt sich aneh

1) M. m. W. 1913 Nr. 36.

2) Bnll. gén. de Thérapeutique 147 p. 139

3) Arch. int. de Pharmak. et de Thér. 121904 p. 215-244. der Privatpraxis; denn hier verordne ich das Recvalysat Kranken, die ich seit zehn Jahren und länger beliandle und wo iclı genalı weiß, wie sie von den bisher gereichten Medikamenten beeinflußt wirden. Drr hierboi beobachtete Untersclied in der Wirkung ließ mich so reelit die Vorzüge dieses nenen Mittels erkennen.

Beiden Geschlechtern jeden Alters gab iel Recvalysat, nnd zwar olne Unterschied in der Wirkıng; bei Kindern fehlen vorerst allerdings genane Beobachtnngen.

Meine Erfalırung stiitzt siclı anf die Auwendung des Reevalysats in den zwei großen Indikationsgebieten:

1. bei Nenrasthenie (Kopfschnerz, Wallungen, Unrulıe, klimakterische Beschwerdenl) und Hysterie;

2. bei sekundären nervösen Klagen, Herzklopfen, Aufregıııszuständen, bei Arteriosklerose, als Naclıkur nach Digitalis nud ähnlicheı Kuren. In allen diesen Fällen, allein nuclı' als 30 ans der Privatpraxis, konnte ich eine gute, typisclie Baldrianwirkung des Recvalysats feststellen.

Daß sie meistens, oft crlieblich, der Wirknng iiberlegen ist, welche die reine offizinelle Baldriantinktur erzengt, hat einen doppelten Grund: Recvalysat stellt ein leiclites Tonicum dar, was sich objektiv feststellen ließ; anderseits ein Sedativun und sogar Hypnoticum. Fs ist so leiclıt kein zweites Mittel zı finden, das diese beiden Wirkungsänßernngen derart gïnstig vereinigt, wie das Recvalysat.

Die Verlangsamıng und Kräftignng des Pulses, sowie die anftretende Bernhignng ist dic bekannte cliarakteristische Ersclieinung des reinen, unzersetzten Baldrians. Ganz besonders ist aber die lyypnotische Wirkıng liervorzuheben, welche ja allerdiıgs nicht stark sein kann, aber nm so elwiinschter ist, als die eigentlichen Hypnotica ja niclit tonisch, sondern elier blutdruckerniedrigend wirken.

Wie oben gesagt, traten anch nach langem Recvalysatgebranch Nebenerscheinungen nicht auf, weder vom Magen, noch voul Darnı, noch sonstwie; ind da der Geschmack als bedeutend besser bezeichnet wird als bei den bekannten Baldrianpraparaten, gelingt eine hinreichend lange Baldriankur mit diesem Dialysat. Neben der gıten Verträglichkeit 
muß besonders erwähnt werden, da $\beta$ dieses Mittel den Appetit des Patienten nicht verdirbt.

Je nach dem Fall betrug die Einzeldosis 10--20-30 Tropfen und wurde ein- bis dreimal täglich genommen, sodaß die gesamte Tagesdosis von 90 Tropfen nie überschritten wirde. Am besten wird es in etwa $50 \mathrm{ccm}$ reinen Wassers dargeboten. Einmal war die Einzeldosis größer als 30 Tropfen; auch hierbei wurde ein ungünstiger Einfluß niclit beobachtet. Für längeren Gebrauch empfiehlt sich nach meiner Erfahrung die dreimalige Darreichung von 20 Tropfen täglich.

Um meine Ausführungen nicht unnötig zu belasten, werden hier absichtlich keine Krankengeschichten mitgeteilt.

Daß ich nach diesen bisherigen Erfolgen Recvalysatum Bürger nicht mehr missen möchte, ist begreiflich; daler möchte ich es auch den Herren Kollegen warm empfehlen. Je länger der Weltkrieg dauert, um so mehr wird er bei Kriegsteilnehmern und bei der Zivilbevölkernng nervöse Erscheinungen auslösen. In allen diesen Fällen, besonders aber bei funktionellen Erkrankungen des Herzens und der Gefüße, auch bəi nosh unklarar Diagnose, kann ich dringend zu einem Versuch mit Recvalysat raten. D Pr Erfolg wird selten ansbleiben, und im Gegensatz zu anderen Mittelı, wie z. B. Brom, eine Schädignng bestimmt nicht anftreten. 